\title{
Objetividad moral sin realismo robusto Comentarios sobre Enoch
}

\author{
Moral Objectivity Without Robust Realism \\ Comments about Enoch
}

José Juan Moreso*

\begin{abstract}
Después de tantas peregrinaciones, por temblores, por nubes y por números, estaba su verdad definitiva. Traspasamos los límites antiguos.

(Pedro Salinas, 'Salvación por el cuerpo',

Razón de amor, 1936)
\end{abstract}

Recepción y evaluación de propuesta: 20/2/2014

Aceptación: 20/03/2014

Recepción y aceptación final: 22/6/2015

Resumen: En este trabajo voy a intentar defender lo que me parece un argumento sólido a favor de la objetividad de la moral y criticar los que me parecen argumentos no concluyentes a favor del realismo moral no-naturalista. Solo me ocuparé de los argumentos en los que Enoch defiende y argumenta la parte constructiva del libro: las tesis fundamentales que caracterizan su enfoque filosófico.

Palabras claves: imparcialidad, objetividad moral, realismo moral.

* Catedrático de Filosofia del Derecho. Universitat Pompeu Fabra, Barcelona. josejuan.moreso@upf.edu. Agradezco a Pau Luque la amable invitación a escribir este ensayo y a un evaluador anónimo de Discusiones por sus comentarios y críticas que, sin duda, han permitido mejorar este texto. La investigación se ha beneficiado de la ayuda financiera del Ministerio español de Economía y Competitividad y de la AGAUR de la Generalitat de Cataluña a los proyectos de investigación DER 2013-48066-C2-1-R y SGR 626. 2014-2, respectivamente. 
José Juan Moreso

\begin{abstract}
In this paper I will try to defend what seems to me a strong argument in favor of the objectivity of morality and criticize what appears to me inconclusive arguments in favor of non-naturalistic moral realism. I only take care of the arguments on which Enoch defends and argues the constructive part of the book: the fundamental thesis that characterize his philosophical approach.
\end{abstract}

Key words: impartiality, moral objectivity, moral realism.

\title{
I. Introducción
}

David Enoch ${ }^{1}$ ha escrito una de las defensas más poderosas y originales del realismo moral. Muchas cosas hacen de su libro una contribución capital a la reflexión filosófica sobre la moral, a la metaética. En la introducción a sus estudios sobre Bentham, H.L.A. Hart ${ }^{2}$ atribuye al padre del utilitarismo una extraordinaria combinación entre una mirada de mosca para el detalle y una mirada de águila para las generalizaciones iluminadoras aplicables a amplias áreas de la vida social. Pues bien, mutatis mutandis, lo mismo puede ser dicho del libro de Enoch. Por una parte, presenta una máxima atención al detalle y el cuerpo del texto junto con sus notas están repletos de argumentos y contraargumentos sobre las cuestiones más intrincadas de la metaética contemporánea. Por otra parte, esta atención al detalle se combina con una mirada amplia para recortar en nuestro horizonte filosófico un lugar bien delimitado y destacado para la reflexión sobre la moralidad, asentada en una defensa vigorosa y fundada de la existencia de hechos y propiedades morales que no son entidades naturales, ni reductibles a ellas, y que basan la verdad, independientemente de las creencias y actitudes de los seres humanos, de los juicios morales ${ }^{3}$.

1 Enoch, D. Taking Morality Seriously. A Defense of Robust Realism, Oxford, Oxford University Press, 2011.

2 Hart, H.L.A. Essays on Bentham. Jurisprudence and Political Philosophy, Oxford, Oxford University Press, 1982.

3 Otras recientes defensas del realismo moral no naturalista, aunque diversas en muchos aspectos de la del autor, en Shafer-Landau, R. Moral Realism: A 
Objetividad moral sin realismo robusto. Comentarios sobre Enoch

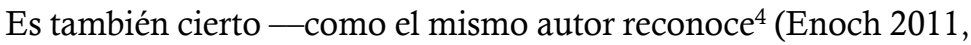
115): "Como podéis haber notado, tengo el temperamento filosófico de un extremista" - que Enoch revela en el libro su propensión hacia las posiciones filosóficas más radicales. Pues bien, dado que yo no tengo dicho temperamento filosófico, sino que tengo un temperamento, por así decirlo, más ecuménico, voy a intentar en este trabajo defender lo que me parece un argumento sólido a favor de la objetividad de la moral y criticar lo que me parecen argumentos no concluyentes a favor del realismo moral no naturalista.

Pero antes, una breve presentación del libro. Tiene diez capítulos. El primero es una introducción y una explicación de los motivos que llevaron a su elaboración. Los capítulos 2 al 5 desarrollan el argumento a favor del realismo moral robusto. Los capítulos 6 al 9 constituyen refinadas réplicas a posibles objeciones a dicha defensa. Y el capítulo 10 es de conclusiones.

No me ocuparé de la segunda parte del libro, destinada a responder las objeciones posibles contra su posición, que contiene muy atinados debates acerca de la aceptabilidad o no de entidades metafísicas sospechosas (cap. 6). El capítulo 7 presenta la objeción epistemológica: la explicación de la correlación entre nuestras creencias normativas y las verdades normativas, que son independientes de nuestras creencias. El capítulo 8 se ocupa de la objeción de la persistente presencia de los desacuerdos morales. El siguiente capítulo se ocupa de los problemas planteados por la motivación y la naturaleza interna o externa de las razones normativas. Concluye con un capítulo en donde trata de presentar las ventajas de su posición $\mathrm{y}$, muy honestamente, cuenta aquellos puntos de su argumentación que le inspiran menos confianza o sobre los que alberga dudas todavía.

Me ocuparé, en cambio, de los argumentos en los que Enoch defiende y argumenta la parte constructiva del libro: las tesis fundamentales que caracterizan su enfoque filosófico. El argumento del capítulo

Defense, Oxford, Oxford University Press, 2003 y Wedgwood, Ralph. The Nature of Normativity, Oxford, Oxford University Press, 2007.

${ }^{4}$ Enoch, D. op. cit. 
2, según el cual las concepciones no objetivistas de la moralidad junto con una tesis normativa muy plausible, que llama imparcialidad, implican juicios morales inaceptables en casos de desacuerdos y conflictos interpersonales. Y el argumento del capítulo 3, conforme al cual las verdades normativas son indispensables para la deliberación práctica, que no es opcional para nosotros, y que tal indispensabilidad justifica el compromiso ontológico con hechos y propiedades morales no naturales, que integran nuestro mobiliario ontológico. El capítulo 4, dice que las dos tesis anteriores, la tesis de la objetividad y la tesis ontológica de la indispensabilidad deliberativa de lo normativo, aunque no implican el realismo moral robusto hacen de él la posición metaética más plausible y acorde con ellas. El capítulo 5, en cambio, trata de mostrar que no es posible obtener dicho resultado con menos compromiso ontológico, que posiciones más parsimoniosas ontológicamente no pueden fundar la indispensabilidad deliberativa.

Procederé como sigue: en el apartado segundo presentaré el argumento de la objetividad, en el siguiente trataré de mostrar la fuerza de dicho argumento, que me parece especialmente perspicuo, en el cuarto reconstruiré el argumento de la indispensabilidad deliberativa de lo normativo, en el quinto ofreceré mis dudas acerca de que sea preciso abrazar un compromiso ontológico tan robusto y en el sexto concluiré.

\section{II.La objetividad desde el argumento de la imparcialidad}

$\mathrm{E}$ l argumento es el siguiente. Supongamos que estamos una tarde en Madrid mi amigo Pablo y yo, y que decidimos pasar la velada juntos porque hace tiempo que no nos vemos. Él propone ir al teatro a ver La Casa de Bernarda Alba de Federico García Lorca, y yo prefiero ir al concierto de la violinista Julia Fischer. No hay ninguna razón por la que uno deba ceder ante la preferencia del otro (algo como que sea la última representación de la obra de teatro, porque se trata de una obra con las mejores críticas y que no volverá a ser representada o algo semejante del concierto). Entonces, se impondría alguna solu- 
Objetividad moral sin realismo robusto. Comentarios sobre Enoch

ción como lo que David Enoch denomina Imparcialidad ${ }^{5}$, de acuerdo con la cual:

En un conflicto interpersonal, debemos retirar nuestras preferencias, o sentimientos, o actitudes, o lo que fuere, y, en la medida en que el conflicto es debido a ellos, se requiere una solución imparcial, igualitaria. Más aún, cada parte del conflicto debe reconocer al menos que mantener la posición propia es, en tales casos, moralmente incorrecto.

La solución puede ser echarlo a suertes, o decidir que ya que estamos en Madrid, que es la ciudad de Pablo, iremos al teatro y cuando nos veamos en mi ciudad, Barcelona, podré decidir yo. Pero sea cual fuera la solución, parece un principio moral incuestionable el de la imparcialidad: en las cuestiones que dirimen meras preferencias todas las preferencias valen igual.

Entonces, el argumento prosigue, si los casos de desacuerdo moral fuesen de este tipo, y la discrepancia entre Pablo y yo se produjera porque Pablo desea acudir a un partido de baloncesto y yo a una corrida de toros, la imparcialidad también se mantendría y las dos partes deberíamos estar dispuestos a retirar nuestra preferencia. Sin embargo, supongamos que Pablo considera que infligir dolor agudo a los animales es inmoral ${ }^{6}$. Y piensa, por lo tanto, que asistir a una corrida de toros para divertirse viendo cómo sufren los animales es inmoral. Entonces, ¿tendría Pablo alguna razón para retirar su punto de vista?

5 Enoch, D., op.cit.

6 Porque es un consecuencialista, que tiene en cuenta los intereses de los animales entre las consecuencias relevantes, como Bentham, Jeremy. An Introduction to the Principles of Morals and Legislation, London, Athlone Press, 1970 y sus seguidores contemporáneos, como Singer, Peter. Animal Liberation, New York, HarperCollins, 1975.; entre nosotros Mosterín, Jesús. ¡Vivan los animales!, Madrid, Debate, 1998,o De Lora, P. Justicia para los animales, Madrid, Alianza, 2003; o menos comprometidamente, porque piensa (como Kant, Immanuel en Lecciones de ética, trad. de R. Rodríguez Aramayo y C. Roldán Panadero, Barcelona, Crítica, 1988) que la crueldad con los animales endurece la sensibilidad moral de los humanos y 'se puede, pues, conocer el corazón humano a partir de su relación con los animales’. 
Parece que no, parece que, al contrario, tendría que mantener su posición y, tal vez, tratar de convencerme a mí de que abandone mi insensibilidad hasta comprender que es incorrecto asistir a la fiesta de los toros. En este caso la imparcialidad no funciona, como no funciona si Pablo y yo discrepamos acerca de cuál es el trayecto más rápido para llegar al Teatro Real de Madrid desde Recoletos a determinada hora del día, si el taxi o el transporte público. Dado que hay una respuesta correcta a esta cuestión de hecho, la imparcialidad aquí no representa ninguna ayuda, ni es racional seguir su regla.

Estas ideas sirven al autor para elaborar un argumento que muestra que las posiciones en metaética que equiparan los juicios morales con expresiones de preferencia personal son falsas y deben por ello ser rechazadas. Aquellas posiciones que sostienen que la verdad de los juicios morales depende de la respuesta que los seres humanos, dadas nuestras creencias y actitudes, damos cuando somos enfrentados a un problema moral son claros candidatos a dicha refutación. Enoch se cuida de mostrarnos que no todas las versiones ${ }^{7}$ que hacen los juicios morales dependientes de la reacción de los humanos son vulnerables a dicha objeción. Hay posiciones, como las constructivistas, que sostienen que dicha respuesta es la que darían seres humanos en condiciones ideales, o bien algunos modos especialmente sofisticados de expresivismo que insisten en que algunas de nuestras respuestas son únicas y permiten la convergencia en el juicio. Dado que algunas de estas posiciones serán discutidas en el apartado IV, podemos ahora quedarnos con el rechazo de las posiciones abiertamente subjetivistas, que hacen depender la moral de nuestras actitudes y sentimientos tal y como los tenemos en la realidad. Para llevarlo a cabo, Enoch formula una posición extrema, en el sentido de que (casi) nadie la defendería en la metaética actual ${ }^{8}$, que denomina subjetivismo caricaturizado:

7 Enoch, D., op. cit.

8 Aunque esto es cierto en la metaética analítica actual, en mi ámbito académico, en la filosofía del derecho analítica de lengua española o italiana, es defendida todavía por autores relevantes. Véase, por ejemplo, Bulygin, E. Essays in Legal Philosophy, Bernal, C., Huerta, C., Mazzarese, T., Moreso, J.J., Navarro, P.E. y Stanley, P., (eds.), Oxford: Oxford University Press, 
Objetividad moral sin realismo robusto. Comentarios sobre Enoch

"Los juicios morales expresan preferencias simples, que están exactamente a la par con una preferencia por jugar al tenis o ir al cine".

Y este es el argumento para la refutación, un argumento que - como puede verse - es una instancia de reductio ad absurdum:

(1) Subjetivismo caricaturizado (para la Reductio)

(2) Si el subjetivismo caricaturizado es verdadero, entonces los conflictos interpersonales debidos a desacuerdos morales son realmente solo conflictos interpersonales debidos a diferencias en meras preferencias (del contenido del subjetivismo caricaturizado).

(3) Por lo tanto, los conflictos interpersonales debidos a desacuerdos morales son solo conflictos interpersonales debidos a meras preferencias (de 1 y 2 ).

(4) Imparcialidad, esto es, más o menos: cuando un conflicto interpersonal (de la clase relevante) es una cuestión meramente de preferencias, entonces una solución imparcial, igualitaria es requerida, y es incorrecto mantener la posición propia.

(5) Por lo tanto, en casos de conflicto interpersonal (de la clase relevante) debidos a desacuerdos morales, una solución imparcial, igualitaria es requerida y es erróneo mantener la propia posición (de 3 y 4 ).

(6) Sin embargo, en casos de conflicto interpersonal (de la clase relevante) debidos a desacuerdos morales a menudo una solución imparcial no es requerida, y es permisible, incluso debido, mantenerse en la propia posición (de la sección previa).

(7) Por lo tanto, el subjetivismo caricaturizado es falso (de 1, 5 y 6, por Reductio).

2015. y Guastini, Riccardo. 'Dei rapporti tra liberalismo e non-cognitivismo', en Teoria Politica, 2012.

9 Estos son los ejemplos que Enoch toma para argüir su caso y que yo he cambiado por ir al teatro o a un concierto. 
Una premisa metaética, el subjetivismo caricaturizado, y una premisa de ética normativa, imparcialidad, implican una consecuencia que está en desacuerdo con (6), la plausible premisa de que en casos de conflictos morales es correcto mantenerse en la posición propia, $\mathrm{y}$ por lo tanto, por reductio, podemos concluir el rechazo de las posiciones no objetivistas en ética.

\section{Vindicando la objetividad}

En mi opinión, el argumento de Enoch es un buen argumento y es un argumento concluyente. Basta que algunos de nuestros conflictos interpersonales deban resolverse por algo como imparcialidad, y que imparcialidad nunca sirva para nuestros conflictos morales. Si esto es así, entonces las metaéticas no objetivistas deben ser rechazadas porque no dan cuenta de este rasgo de nuestra moralidad.

Las objeciones, como ha de resultar claro, al argumento de Enoch pasan por poner en duda la distinción entre conflictos interpersonales de meras preferencias y los conflictos interpersonales por razones morales. Es más pasan por tratar de mostrar que hay casos de conflictos interpersonales no morales en donde la imparcialidad no debería imponerse y que hay casos de conflictos interpersonales morales donde la imparcialidad debería mantenerse ${ }^{10}$.

Veamos dos ejemplos ${ }^{11}$ que tratan de mostrar esta inadecuación de la distinción del autor. Primero, un caso debido a un conflicto de desacuerdo no moral en el cual no es razonable abandonar la posición

${ }^{10}$ Manne, Kate y Sobel, David en su artículo "Disagreeing about how to disagree", Philosophical Studies, 2014, critican a Enoch con estos argumentos y proponen una estrategia alternativa, consistente en sostener que debemos mantener nuestra posición cuando el conflicto sea suficientemente importante, independientemente de su naturaleza de meras preferencias o moral. Creo, por las razones que esgrime Enoch (2014) en su respuesta, que esta estrategia no funciona.

${ }^{11}$ Wedgwood, R. "Book Review: Taking Morality Seriously. A Defense of Robust Realism. By David Enoch, Oxford, Oxford University Press, 2011", en The Philosophical Quarterly, 2013. 
Objetividad moral sin realismo robusto. Comentarios sobre Enoch

propia. "Supongamos — dice Wedgwood en su primer ejemplo- que eres el miembro de una comisión que ha de conceder un premio a cierta obra de arte y estás en total desacuerdo con los otros miembros de la comisión". Se trata de un desacuerdo no de origen moral sino estético. Pero no sería incorrecto moralmente que mantuvieras tu posición y expresaras públicamente tu desacuerdo.

Es claro que Wedgwood lleva razón. Pero no es claro por qué este argumento vaya contra Enoch. En primer lugar, Enoch se cuida mucho de decir que hay muchos casos de conflictos interpersonales en los que no impera la imparcialidad, este principio solo impera cuando los conflictos son de meras preferencias y se dan determinadas circunstancias del contexto que no llevan a otra solución. En segundo lugar, en el caso del premio a la obra de arte o bien creemos que hay cánones estéticos de corrección - como yo mismo me inclino a aceptar-, y entonces no hay razones para abandonar aquello que creemos que es correcto, o bien no los hay y entonces este conflicto puede ser meramente de preferencias y debería decidirlo la imparcialidad.

El segundo ejemplo - un caso de conflicto de origen moral, en donde retirar la propia posición tiene sentido- alberga, creo, mayor interés:

El ejemplo de Enoch de un conflicto interpersonal debido a desacuerdo moral es el de la importancia moral de evitar la crueldad con los perros. Pero supongamos que estamos involucrados en un desacuerdo de este tipo, digamos, acerca de si la caza del zorro debe ser jurídicamente prohibida. Si no hay esperanza por nuestra parte de persuadir a los demás de que cambien su punto de vista, entonces parece correcto para todos acordar en resolver el conflicto por medio de un procedimiento democrático, incluso si todos estamos de acuerdo en que hay una probabilidad alta de que el resultado de este procedimiento democrático pueda ser moralmente subóptimo.

También aquí Wedgwood lleva razón en que parece correcto deferir a la mayoría democrática la solución del caso. Pero, de nuevo, esto no sirve contra Enoch. Aceptamos que el caso de la caza del zorro es un caso de desacuerdo de origen moral, ahora bien, nadie 
tiene —ni después de la decisión democrática- porqué abandonar su posición moral. Al contrario, esperamos que los abolicionistas sigan manteniendo su posición a la espera de convencer a los demás. Los procedimientos democráticos no son, creo, una implementación de imparcialidad. Son modos de tomar decisiones en casos de desacuerdo igualmente respetuosas de la autonomía de todos, confiando en que la deliberación de todos nos llevará a acertar con los resultados correctos a menudo, y dando legitimidad a esa solución. Pero ello de ningún modo significa que los que quedan en minoría abandonan su posición. Este es precisamente uno de los problemas centrales de la filosofía política: ¿cómo hacer compatible la legitimidad política de decisiones erróneas con el punto de vista moral? Por otra parte, el procedimiento democrático para muchos se funda precisamente en el valor epistémico del que goza, cuando opera en condiciones óptimas, para alcanzar resultados justos desde el punto de vista moral ${ }^{12}$.

Sin embargo, el mismo Enoch reconoce que desde las concepciones no objetivistas de la ética es más difícil justificar el hecho de mantenerse en la propia posición en casos de conflicto moral y lo hace en los siguientes términos:

Se sugiere algunas veces - aunque más a menudo en las aulas que en los textos filosóficos-que las concepciones realistas en metaética conducen a la intolerancia, y que esto ofrece una razón para rechazarlas. Considero este punto de vista confundido de diversas maneras ( $\mathrm{y}$ esta es una buena razón por la cual no aparece en textos filosóficos serios). Pero hay algo correcto en él, algo capturado por el argumento en el texto: desde las concepciones no objetivistas de la moralidad, es más difícil justificar el mantenerse en la propia posición moral cuando

${ }^{12}$ Nino, C. The Constitution of Deliberative Democracy, New Haven, Yale University Press, 1996; Martí, J.L. "The Epistemic Conception of Deliberative Democracy Defended. Reasons, Rightness and Equal Political Autonomy" in S. Besson, J.L. Martí (eds.), Deliberative Democracy and Its Discontents, Aldershot, Ashgate, cap. 2, 2006; Estlund, D.M., Democractic Authority: A Philosophical Framework (Princeton: Princeton University Press), 2009. 
Objetividad moral sin realismo robusto. Comentarios sobre Enoch

nos enfrentamos con conflictos o discrepancias. Pero, claro, considero este rasgo como una ventaja de los puntos de vista objetivistas.

En mi ámbito académico más cercano, como apunto en la nota 4, que es el de la filosofía jurídica en España, Latinoamérica e Italia, tal posición es defendida apasionadamente no solo en las clases sino también en seminarios y congresos diversos. Algunas veces es también argüida en textos filosóficos serios. Ferrajoli defendía, por ejemplo, que el cognoscitivismo y el objetivismo ético llevan inevitablemente al absolutismo moral y, en consecuencia, a la intolerancia con las opiniones disidentes. Y añadía, incluso: "bajo este aspecto, el objetivismo y el cognoscitivismo moral más coherentes son, sin duda, los expresados por la moral católica"13.

Y Guastini ${ }^{14}$ acepta que es cierto que ninguna premisa metaética puede fundar lógicamente conclusiones de ética normativa, sin embargo, según su opinión, una ética liberal (de la tolerancia) puede constituir una buena razón pragmática para adoptar una metaética no cognoscitivista y no objetivista. Y viceversa.

Las razones que ofrece el autor para basar esta tesis son las siguientes: sostiene plausiblemente que las éticas normativas dispondrán de alguna norma de conducta referida a cuál ha de ser la actitud frente a las otras éticas normativas. Y añade que las éticas liberales asumirán una de las dos siguientes metanormas:

13 Aunque tal vez ahora estaría dispuesto a morigerar dicha posición extrema (vd. Ferrajoli, L. 'Constitucionalismo principialista y constitucionalismo garantista', en Doxa. Cuadernos de Filosofia del Derecho, 2011; y Ferrajoli, L.; Ruiz Manero, J. Dos modelos de constitucionalismo. Una conversación, Madrid, Trotta, 2012. a menudo como consecuencia de su diálogo con Ruiz Manero). Me he ocupado de ello en Moreso, J.J. "Antígona como defeater. Sobre el constitucionalismo garantista de Ferrajoli', en Doxa, 2012. Y Moreso, J.J. "Ethica more iuridico incorporata: Luigi Ferrajoli', en Anuario de filosofia del derecho, $2013 \mathrm{~b}$.

${ }^{14}$ Critico estas ideas en Moreso, J.J. "Donde la pala se nos dobla. De nuevo sobre metaética y política”, en Teoría Política, 2013a. 
José Juan Moreso

(Ni) Cualquier otra ética normativa (diversa de esta) debe ser tolerada,

(Nii) Solo algunas éticas normativas (diversas de estas) deben ser toleradas, mientras que las éticas intolerantes, y por lo tanto no liberales, asumirán una metanorma como la siguiente:

(Niii) No debe tolerarse ninguna otra ética normativa diversa de esta.

Como puede observarse, estos argumentos consideran que el liberalismo de la tolerancia y la democracia encajan mejor con las metaéticas no objetivistas. Tal vez, porque asumen para las preferencias morales un postulado como imparcialidad. Sin embargo, creo que se trata de un mal argumento. Es cierto que algunas veces las decisiones democráticas deben tomar partido entre preferencias indiferentes desde el punto de vista moral y, entonces, el respeto a las opiniones de todos hace de la regla de la mayoría la solución sobresaliente. Hay algunos ejemplos claros de ello: hace unos pocos años en mi ciudad, Barcelona, el Ayuntamiento propuso un referéndum para decidir si la Diagonal, una de las arterias más importantes de la ciudad, a la que se quería convertir en una avenida más amable con los peatones, debía ser urbanizada como una rambla (con un paseo amplio para los peatones en el centro) o como un bulevar (un paseo a ambos lados de la vía, con el lugar para la circulación motorizada en el centro $)^{15}$. Es obvio que en casos como este, algo como imparcialidad debe imponerse, y también parece obvio que ello exige - en casos de desacuerdos en un grupo amplio - una decisión mediante la regla de la mayoría, el único modo capaz de respetar por igual las preferencias de todos. Es una cuestión controvertida cuántas de las decisiones políticas habitan en este rango, pero parece obvio que algunas lo hacen: la ordenación de las prioridades y la distribución de los recursos entre salud y educación puede servir de ejemplo. A partir de la satisfacción de determinado umbral, la cuestión de si financiar primero la construcción

${ }^{15}$ Las circunstancias políticas de la consulta, que ahora no interesan, hizo que se impusiera una tercera propuesta, consistente en dejar la avenida como estaba. 
Objetividad moral sin realismo robusto. Comentarios sobre Enoch

de una nueva escuela o de un nuevo centro de salud puede ser una cuestión de preferencias ya no resoluble mediante argumentos morales, por ejemplo.

Ahora bien, que la igual consideración de todos sea un elemento central del liberalismo democrático en ningún caso conlleva que sea el único elemento. Cuando discutimos sobre la inclusión de la pena de muerte en nuestro sistema de sanciones penales, del derecho al voto de las mujeres, del acceso universal al sistema de educación o al sistema de salud y, también, según creo, de la autorización de la caza del zorro, discutimos sobre cuestiones morales y ahí la imparcialidad no sirve para dirimir la cuestión. Si aceptamos que la democracia puede resolver estos supuestos no es solo porque creemos que la igual consideración y respeto de la voluntad de todos es clave, sino también porque pensamos que los procedimientos democráticos, que incluyen la deliberación genuina que toma en cuenta las opiniones de todos, aumentan nuestra capacidad de hallar respuestas correctas desde el punto de vista moral, porque la democracia tiene, como argüía más arriba, valor epistémico ${ }^{16}$. En este sentido, la noción de legitimidad democrática presupone el objetivismo ético ${ }^{17}$. Presupone que, en los casos de conflicto moral, no tenemos razones para retirar nuestra propia posición y que las posiciones que conciben los juicios morales como meras expresiones de preferencia personal son inadecuadas.

${ }^{16}$ Obviamente queda por resolver la controvertida cuestión de si para alcanzar dicho resultado es más adecuado atrincherar previamente algunos elementos, configurados como las precondiciones, como derechos básicos y sustraerlos a la agenda política ordinaria. La vexata quaestio de la justificación de la judicial review tiene, como resultará obvio, mucha relación con ello. Lamentablemente no es este el lugar para decir nada más sobre este problema. Pero puede verse una defensa de algo como imparcialidad, echarlo a suertes, para las decisiones sobre la constitucionalidad de las leyes como alternativa superior a la decisión de un Tribunal en Marmor 2015.

${ }^{17}$ Un perspicuo argumento en este sentido se encuentra en Martí, J.L., "Democracia y subjetivismo ético", en Teoría Política, 2012. 
José Juan Moreso

\section{La indispensabilidad deliberativa de lo normativo}

Los denominados argumentos de la indispensabilidad proceden de la filosofía de las matemáticas y fueron desarrollados por Quine y Putnam $^{18}$. La siguiente formulación del argumento ${ }^{19}$ puede tomarse como punto de partida:

(P1) Debemos comprometernos ontológicamente con todas y solo a aquellas entidades que son indispensables para nuestras teorías cientificas.

(P2) Las entidades matemáticas — como los números, las funciones, las clases - son indispensables para nuestras teorías matemáticas.

(P3) Debemos comprometernos ontológicamente con las entidades matemáticas.

De un modo semejante al que, en filosofía de la ciencia, es aceptada la existencia de las denominadas entidades teóricas (los electrones, los agujeros negros, por ejemplo) — porque la mejor explicación de la realidad que la física nos ofrece así lo presupone-, ha de ser aceptada la existencia de estas entidades abstractas presupuestas por nuestra teorías científicas ${ }^{20}$. En general, un argumento de la indispensabilidad

18 Quine, W. V.O., "Things and Their Place in Theories", en W. V.O. Quine, Theories and Things, Cambridge, MA, Harvard University Press, 1981, pp. 1-23; Putnam, H. "Philosophy of Logic", reprinted in H. Putnam, en Mathematics Matter and Method: Philosophical Papers, Volume 1, (2nd edition), Cambridge, Cambridge University Press, 1979, pp. 323-357.

${ }^{19}$ Colyvan, M. "Indispensability Arguments in the Philosophy of Mathematics", en The Stanford Encyclopedia of Philosophy, Spring 2015 Edition, E. N. Zalta (ed.), 2015.

${ }^{20}$ Este es un argumento distinto de lo que se conoce como argumento mooreano, que establece, por ejemplo, que vale la inferencia de 'Hay números naturales mayores que 100' a 'Hay (existen) números naturales'. O, de manera semejante, 'torturar bebés para divertirse es incorrecto moralmente' podemos transitar a 'hay un hecho moral que es incorrecto torturar bebés para divertirse', es decir, 'hay (existen) hechos morales'. Y, por lo tanto, tenemos razones para 
es un argumento que garantiza la verdad de determinada proposición basada en la indispensabilidad de dicha proposición para algún propósito establecido. Si el fin, como en el caso del anterior argumento, es la explicación, entonces podemos decir que se trata del argumento de la indispensabilidad explicativa.

En esta literatura, por otra parte, se reconoce ${ }^{21}$ que los argumentos a la mejor explicación — como un argumento a favor de la existencia de los protones porque nuestras mejores teorías científicas cuantifican sobre protones y tenemos confianza en su verdad-, son en realidad instancias de los argumentos de la indispensabilidad. Sin embargo, Enoch es consciente de que la indispensabilidad explicativa de las entidades normativas es controvertida: no forman parte de lo que presuponen nuestras mejores teorías científicas. Lo que el autor quiere mostrar es la indispensabilidad deliberativa de lo normativo. Es decir, que cuando delibero, por ejemplo, acerca de a qué escuela inscribir a mi hija, entonces me involucro en una tarea que presupone que hay una respuesta correcta a esta cuestión y que dicha respuesta no depende de mí, sino que hay alguna verdad normativa que hace correcto inscribirla en una escuela en lugar de otra. De no ser así, ¿qué sentido tendría mi deliberación? Por otro lado, arguye Enoch, la deliberación es algo no opcional para agentes como nosotros que enfrentamos este tipo de cuestiones prácticas. Y, además, deliberar es distinto de escoger (una carta de un mazo, una botella de agua en el supermercado de una fila de botellas de la misma marca y tamaño): cuando deliberamos nos comprometemos con la decisión, creemos que es la mejor decisión que podíamos tomar, eliminamos la arbitrariedad mediante el descu-

rechazar las teorías del error en matemáticas y en moral. Como resultará claro, este argumento es deudor del argumento de Moore (Moore, G.E. "Proof an External World", en Proceedings of the British Academy, 1939) en contra del escéptico respecto de la existencia del mundo externo. Véase también, por ejemplo, Fine, Kit, “The Question of Realism”, en Philosophers' Imprint, 2001. Enoch usa este argumento contra las teorías del error en metaética, pero no como fundamento de su defensa del realismo normativo robusto. Por ello, su plausibilidad no será analizada aquí.

${ }^{21} \mathrm{Y}$ así lo hace también Enoch D., op. cit., pág. 55 
brimiento de las razones para tomar la decisión.

$Y$ en este sentido, para el autor, hay un espacio para argumentos de la indispensabilidad diferentes de la indispensabilidad explicativa, entre ellos, la indispensabilidad deliberativa. Con estas ideas, Enoch elabora el siguiente argumento:

(1) $\mathrm{Si}$ algo es instrumentalmente indispensable para un proyecto intrínsecamente indispensable, entonces estamos justificados (epistémicamente y por esa genuina razón) en creer que dicha cosa existe.

(2) El proyecto deliberativo es intrínsecamente indispensable.

(3) Las verdades normativas irreductibles son indispensables para la deliberación práctica.

(4) Por lo tanto, estamos epistémicamente justificados en creer que hay verdades normativas irreductibles.

En el capítulo cuarto el autor combina los argumentos de los dos capítulos anteriores para defender el realismo moral robusto. No sostiene que la tesis del rechazo de las metaéticas no objetivistas junto con la tesis de la indispensabilidad deliberativa de lo normativo implican el realismo moral robusto, sino que lo hacen muy plausible ${ }^{22}$.

$\mathrm{Y}$ en el capítulo 5 el autor rechaza otras posiciones que prometen lo mismo que ofrece el realismo moral robusto con mayor parsimonia filosófica: naturalismo, ficcionalismo, teorías del error y lo que denomina quietismo, en donde sitúa todas aquellas posiciones que consideran que el discurso metanormativo o bien es ininteligible porque (parcialmente) la práctica normativa no precisa ninguna justificación externa o bien que es discurso normativo de primer orden camuflado.

${ }^{22}$ Aunque cabe un constructivismo sofisticado acerca de lo normativo combinado con una teoría del error para la moral (vd. Joyce, R. "Metaethical Pluralism: How both Moral Naturalism and Moral Skepticism May Be Permissible Positions", S. Natucelli, G. Seay (eds.), en Ethical Naturalism: Current Debates, (Cambridge: Cambridge University Press), 2012, una posibilidad advertida, pero no discutida, por Enoch. 
Objetividad moral sin realismo robusto. Comentarios sobre Enoch

Al final del capítulo 2, había ya rechazado, por no dar cuenta de la objetividad del discurso moral, algunas formas constitutivistas del constructivismo y, también, el expresivismo.

Con estos argumentos, se puede resumir el argumento del libro del siguiente modo, como elegantemente hace Faraci ${ }^{23}$ :

(1) Las creencias morales refieren a algo objetivo.

(2) Si los hechos normativos robustos son indispensables para la deliberación, tenemos alguna razón para creer en ellos, y para aceptar de este modo el realismo metanormativo robusto.

(3) En la medida en que tenemos razón para aceptar el realismo metanormativo robusto, tenemos razón para aceptar el realismo metaético robusto.

(4) Los hechos normativos robustos son indispensables para la deliberación puesto que las alternativas que son consistentes con (1) y con el lugar de la normatividad en la deliberación fracasan.

(5) Ninguna de las objeciones metafísicas, epistemológicas, semánticas o psicológicas al realismo robusto son significativamente lesivas.

(6) Por lo tanto, tenemos las mejores razones para aceptar el realismo robusto a la vez en metaética y en teoría metanormativa.

Como Faraci arguye (2012), casi todos los filósofos hoy en día aceptarían (1). Solo quedarían excluidas aquellas metaéticas que no dan cuenta de la objetividad: posiciones eliminacionistas, el subjetivismo caricaturizado o el crudo emotivismo ${ }^{24}$. También aceptarían, según creo, que (2), obsérvese que es una premisa condicional, es verdadera si el antecedente es falso. Y una gran mayoría aceptaría (3),

${ }^{23}$ Faraci, D. "Book Review: David Enoch, Taking Morality Seriously. A Defense of Robust Realism", (Oxford: Oxford University Press, 2011)', en The Journal of Value Enquiry, 2012.

${ }^{24}$ En Moreso 2003, 2008 trato de mostrar porqué estas concepciones no son capaces de capturar las platitudes que subyacen a la práctica de la moralidad. 
aunque algunos ${ }^{25}$ podrían aceptar las razones normativas y rechazar las razones morales robustas en virtud de las características de dichas razones, que son categóricas, que están intrínsecamente unidas a la motivación a pesar de ser externas, etc ${ }^{26}$. Las dudas son acerca de la plausibilidad de las premisas (4) y (5), como resultará obvio y de ello me ocupo en el siguiente epígrafe.

\section{Parsimonia: entia non sunt multiplicanda praeter necessitatem}

Enoch acepta una versión del principio de parsimonia: las clases de entidades no deben ser multiplicadas innecesariamente, la redundancia debe ser evitada, una versión de la conocida navaja de Ockham. Se trata de una versión mínima puesto que Enoch acepta que solo deben ser aceptadas aquellas entidades que son indispensables, pero no solo las explicativamente indispensables, como una versión más fuerte del principio.

La cuestión, entonces, se focaliza en si necesitamos aceptar verdades normativas que nos comprometen con la existencia de hechos y propiedades no naturales. Es decir, si las verdades normativas (como que no se debe torturar a los bebés para divertirse) presuponen la existencia genuina de hechos y propiedades morales en nuestro mobiliario ontológico.

Hay muchos intentos en la literatura de preservar las verdades normativas y rechazar el compromiso ontológico. El mismo expresivismo

${ }^{25}$ Mackie, J., Ethics. Inventing Right and Wrong, Harmondsworth, Penguin, 1977.

${ }^{26}$ Véase Joyce Joyce, R., "Metaethical Pluralism: How both Moral Naturalism and Moral Skepticism May Be Permissible Positions", S. Natucelli, G. Seay (eds.), en Ethical Naturalism: Current Debates, (Cambridge: Cambridge University Press), 2012. "Book Review: Taking Morality Seriously: A Defense of Robust Realism by Enoch, David”, en Ethics, 2013. 
Objetividad moral sin realismo robusto. Comentarios sobre Enoch

cuasirealista ${ }^{27} \mathrm{o}$ la distinción entre propiedades y $\operatorname{conceptos}^{28}$ es una ruta que promete verdades morales sin asumir el compromiso ontológico. Por otra parte, el realismo moral naturalista en sus diversas formas trata de mostrar cómo son posibles las verdades morales, aunque las propiedades morales son en algún modo reducibles a propiedades naturales ${ }^{29}$.

No obstante, supongamos que podemos dar por buenas las críticas a estas concepciones que ha elaborado el autor, y que por lo tanto aceptamos que hay algo como verdades morales irreductibles. ¿Nos compromete esta posición ontológicamente? ¿Debemos aceptar entonces el realismo moral robusto? La verdad es que creo que no tenemos razones decisivas para hacerlo. Tomaré, como ejemplo de lo que quiero decir las objeciones del autor a dos enfoques distintos: el constructivismo constitutivista y el quietismo y argüiré que sus razones contra estas posiciones no son decisivas. Y dejaré de lado sus objeciones a la teoría del error y al ficcionalismo, aunque todas estas concepciones metaéticas se solapan entre ellas, es claro ${ }^{30}$.

Un argumento central de Enoch contra el constitutivismo es que la agencia racional de los sujetos morales es opcional, por lo tanto no sirve para fundar nuestra práctica moral. Sin embargo, no es claro por qué la

${ }^{27}$ Blackburn, S., Essays in Quasi-Realism, Oxford, Oxford University Press, 1993.

${ }^{28}$ Gibbard, A., Thinking How to Live, Cambridge, Mass., Harvard University Press, 2003.

${ }^{29}$ El mismo Enoch muestra sus dudas relativas a las objeciones al reduccionismo naturalista y deja abierta la posibilidad de que algo análogo en metaética al monismo anómalo en filosofía de la mente resulte defendible. Véase por todos Schroeder, M., "Realism and Reduction: The Quest of Robustness", en Philosopher's Imprint, 5 (1), 2005.

${ }^{30}$ Así pueden contemplarse, por ejemplo, posiciones a la búsqueda de una posición intermedia entre el realismo platonista y el anti-realismo (Mcdowell, John. "Values and Secondary Qualities" en T. Honderich, Morality and Objectivity, London, Routledge \& Kegan P., 1985) o posiciones que asumen una metaética ambivalencia entre el naturalismo y el escepticismo (Joyce, R., "Metaethical Pluralism: How both Moral Naturalism and Moral Skepticism May Be Permissible Positions", S. Natucelli, G. Seay (eds.), en Ethical Naturalism: Current Debates, (Cambridge: Cambridge University Press), 2012. 
agencia racional es opcional y la deliberación es indispensable y no opcional, que es una premisa necesaria del argumento de Enoch para fundar su tesis de la indispensabilidad deliberativa. Es decir, para Enoch, la deliberación es racionalmente no opcional y ha presentado, como vimos, buenas razones para ello; entonces no acaba de comprenderse por qué, en cambio, su crítica a los constructivismos metaéticos de carácter constitutivo es que la agencia racional es opcional, que necesitamos una respuesta de porqué debemos ser un agente racional al fin y al cabo ${ }^{31}$.

Aunque mis simpatías están con la plausibilidad de un enfoque constructivista en metaética ${ }^{32}$, estas concepciones han sido objeto de la crítica reiterada y detallada de Enoch y por dicha razón su análisis pormenorizado deberá esperar otra ocasión. Aquí solo se quiere poner de manifiesto que si, como premisa del argumento de la indispensabilidad, se puede establecer como no opcional la deliberación racional, tal vez también haya un modo de considerar no opcional la agencia racional, como premisa para averiguar precisamente aquello que debemos hacer y derivar de sus elementos constitutivos los juicios morales

${ }^{31}$ Vd. Faraci, D. "Book Review: David E., op. cit., en The Journal of Value Enquiry, 2012., criticando este aspecto concretamente, Lenman, James. "Deliberation, Schmeliberation: Enoch's Indispensability Argument", en Philosophical Studies, 2014. Sobre los presupuestos de la indispensabilidad $y$, en general, Ferrero, Luca. "Constitutivism and the Inescapibility of Agency", en Oxford Studies in Metaethics, 2009.

${ }^{32}$ En Moreso 2008 por ejemplo. Una concepción que, como es obvio, tiene su origen en la filosofía práctica kantiana y ha sido modernamente desarrollada por autores como Rawls, John. "Kantian Constructivism in Moral Theory", Journal of Philosophy, 77, 1982., Habermas, Jürgen. "Etica del discurso. Notas para un programa de fundamentación", en Conciencia moral y acción comunicativa, trad. de R. García Cotarelo, Barcelona, Península, 1985., Nino, C.S., El constructivismo ético, Madrid, Centro de Estudios Constitucionales, 1989. Korsgaard, C., The Sources of Normativity, Cambridge, Cambridge University Press, 1996, Scanlon, T., What We Owe to Each Other, Cambridge, Mass., Harvard University Press, 1988. Una perspicua presentación general en Bagnoli, C., "Constructivism in Metaethics", en The Stanford Encyclopedia of Philosophy, Edward N. Zalta (ed.), 2015. 
Objetividad moral sin realismo robusto. Comentarios sobre Enoch

correctos $^{33}$. Y, si ello fuese posible, entonces podríamos dar cuenta de la objetividad de la moral sin comprometernos con la existencia de hechos y propiedades morales en el sentido robusto que Enoch postula.

Un modo alternativo de defender la irreductibilidad de las verdades morales sin asumir una ontología platónica ha sido desarrollado en el ámbito de lo que Enoch denomina como quietismo ${ }^{34}$. Como sabemos, esta posición sostiene que las cuestiones ontológicas son internas a su propio ámbito y, en la medida en que no colisionan con otros ámbitos —en especial con el ámbito de las ciencias empíricas- su validez interna es suficiente para su verdad, sin que sea necesario postular externamente su existencia y comprometerse ontológicamente ${ }^{35}$. Como Enoch sostiene que de este modo - una posición cercana al ficcionalismo - podemos afirmar que los números existen, aunque ello solo significa que el discurso matemático los toma como variables de su cuantificación junto con la ausencia de colisión de estas afirmaciones con las verdades de las ciencias empíricas. De un modo similar aceptamos la verdad de 'Sherlock Holmes vive en Londres', entendido como una verdad interna a la ficción de Conan Doyle, como 'En la ficción C. Doyle, Sherlock Holmes vive en Londres'. No hay solo una noción de existencia, sino varias nociones de existencia. Hay modos de existir que no tienen implicaciones causales ni requieren la ocupación de un lugar espacio-temporal.

${ }^{33}$ Que ello es posible ha sido defendido, con especial referencia a las críticas de Enoch, recientemente por Street, Sharon, "What is Constructivism in Ethics and Metaethics?", en Philosophy Compass, 2010. Smith, M., "A Constitutivist Theory of Reasons: Its Promise and Parts", en Law, Ethics and Philosophy, 1, 2013.

${ }^{34}$ Un término que no es del agrado de los autores encuadrados en su ámbito. Con humor, Enoch cuenta que Tom Nagel y Ronald Dworkin amenazaron, cariñosamente, con calificar la posición del realismo moral robusto como chillonismo ('loudists' o 'shoutists').

${ }^{35} \mathrm{Tal}$ vez sea Ronald Dworkin (Dworkin, R., "Objectivity and Truth: You'd Better Believe It", en Philosophy and Public Affairs, 1996. --- Justice for Hedgehogs, Cambridge, Mass., Harvard University Press, 2011.) el autor que más ha insistido en la imposibilidad de adoptar esa perspectiva externa, ese punto de vista arquímediano, en estos asuntos. 
La crítica de Enoch a tal punto de vista es que no sirve para suministrarnos una noción adecuada de verdad moral. Podríamos imaginar una operación distinta a la deliberación, la contradeliberación, que considera, por ejemplo, que el hecho de causar dolor es siempre una razón a favor de realizar una acción y así sucesivamente, y dicha operación generaría un espacio de razones internas, que no colisionan con las verdades de la ciencia, y no podríamos negarles la existencia.

Pues bien, recientemente Parfit ${ }^{36}$ ha elaborado un conjunto de argumentos para distinguir entre varios tipos de existencia, donde hay lugar para las verdades matemáticas y para las verdades morales sin compromiso ontológico.

Parfit comienza con una posición sumamente restrictiva:

Fundamentalismo: Todo lo que existe son los últimos constituyentes de la realidad.

Según tal punto de vista, solo existen las partículas subatómicas, y no hay ni átomos, ni estrellas, ni sillas. Es, como Parfit sostiene, un punto de vista muy implausible. El hecho de que muchos objetos físicos sean compuestos, en el sentido de que están hechos de elementos más pequeños, es consistente con la existencia de estos objetos, que no existen separadamente de sus componentes.

Otro punto de vista, menos restrictivo que el anterior es:

Actualismo: Ser, o existir, es ser real -actua-, esto es no puede haber algo que sea meramente posible.

Pero entonces, sigue Parfit, no elegiríamos entre varios actos posibles, ni tendríamos razones para arrepentirnos de lo que no hicimos, por ejemplo. El actualismo no es tampoco plausible, debemos adoptar algo como :

Posibilismo: Hay algunas cosas que nunca son reales, sino que son meramente posibles. Hay algunas cosas que podrían ocurrir pero realmente nunca ocurrieron y algunas cosas que podrían existir pero nunca existen realmente.

${ }^{36}$ Parfit, D., On What Matters. Volume Two, Oxford, Oxford University Press, 2011. 
Objetividad moral sin realismo robusto. Comentarios sobre Enoch

Por dicha razón, Parfit rechaza que las palabras 'hay' o 'existe' deban siempre usarse en el mismo sentido único y adopta un punto de vista plural con un sentido restringido de 'existir', según el cual las cosas que existen son partes concretas del mundo espacio-temporal, y hay otro sentido más amplio según el cual hay los actos y las cosas posibles.

La existencia de los mundos posibles es una cuestión, como es obvio, altamente controvertida en filosofía y aquí la traemos a colación solamente para mostrar cómo Parfit sostiene que hay otros candidatos a la existencia, como los números, las proposiciones, las verdades lógicas o las razones normativas que no existen en ninguno de los sentidos anteriores.

Comencemos con los números y las verdades matemáticas. Según Parfit:

Algunos ejemplos, sugiero, son verdades matemáticas. Nada puede ser más verdadero que las verdades que 2 es mayor que 1 , que $2+2=4$ y que hay números primos mayores que $100 \mathrm{Ni}$ siquiera Dios podría hacer estos juicios falsos. Para que estos juicios sean verdaderos, ha de haber algún sentido en que haya números, o en que los números existan. Pero al decidir qué juicios matemáticos son verdaderos, no necesitamos contestar a la pregunta de si los números realmente existen en un sentido ontológico, aunque no en el espacio y en el tiempo. Similares observaciones se aplican a algunas otras entidades abstractas, como las verdades lógicas y los argumentos válidos.

Y este es también el tipo de existencia de los hechos y razones normativos que carecen de estatus ontológico:

Hay algunos juicios que son irreduciblemente normativos en el sentido de que comportan razones, y que son en el sentido más fuerte verdaderos. Pero estas verdades no tienen implicaciones ontológicas. Para que tales juicios sean verdaderos, estas propiedades que comportan razones no necesitan existir ni como propiedades naturales en el mundo espacio-temporal, ni en alguna parte de la realidad no-espacio-temporal. 
Esta es una posición que rechaza el naturalismo, una posición cognoscitivista y racionalista, pero no es una posición comprometida metafísicamente. Se trata de lo que Parfit denomina un cognoscitivismo normativo no-naturalista y no-metafísico.

Si este es un punto de vista ontológicamente plausible, entonces hay verdades normativas irreductibles sin compromiso a un realismo robusto, sin compromiso ontológico. Obviamente, para mostrar que es un punto de vista ontológicamente plausible hay que mostrar que la práctica de la moralidad produce juicios objetivos, en los que agentes racionales y razonables convergerían. Y para ello sería necesario un análisis detallado de la impresionante contribución de Parfit en debate con las otras grandes contribuciones a los fundamentos de la ética. Lo que está más allá de los propósitos de esta contribución. Aquí basta con sostener que hay concepciones, como la de Parfit, en las que queda un espacio para las verdades normativas irreductibles sin hechos normativos robustos, que hay un espacio para la objetividad moral sin platonismo, como hay un espacio para la objetividad de las matemáticas sin platonismo.

\section{Conclusión: objetividad y principio de tolerancia}

La significativa contribución de Enoch, en mi opinión, nos ofrece buenas razones para rechazar las metaéticas que no dan cuenta de la objetividad de la práctica moral. No conozco a ninguna persona racional que sostenga que es correcto torturar a los bebés para divertirse y esta es una buena razón para creer en la verdad objetiva de dicha afirmación, una verdad que no depende de nuestras creencias y deseos presentes.

Sin embargo, sus argumentos para defender que dicha objetividad ha de fundarse en el realismo moral robusto, en la existencia de propiedades y hechos no naturales me parece más cuestionable. Al fin y al cabo, la práctica de las matemáticas y su objetividad no se ve amenazada en absoluto porque los filósofos de las matemáticas sigan debatiendo si los fundamentos ontológicos de tal práctica comprometen con el platonismo o bien algún tipo de enfoque constructivista $o$ 
Objetividad moral sin realismo robusto. Comentarios sobre Enoch

ficcionalista puede resultar suficiente. De un modo similar, podemos seguir discutiendo en metaética acerca de los fundamentos ontológicos más adecuados para la moralidad, porque si garantizamos la objetividad de dicha práctica, nuestros debates de ética normativa podrán ser sometidos a la racionalidad. Podemos practicar, ecuménicamente, lo que una vez - referido a la filosofía de las matemáticas-Carnap${ }^{37}$ denominó el principio de tolerancia:

Esta actitud neutral en relación con las diversas formas de lenguaje filosófico, basada en el principio de que cada uno es libre de utilizar el lenguaje más adecuado a su objetivo, ha permanecido inalterable durante toda mi vida. En Logical Syntax lo formulé como 'el principio de tolerancia' y aún lo mantengo hoy en día, por ejemplo, con respecto a la controversia contemporánea sobre el lenguaje nominalista y el lenguaje platónico.

Al fin y al cabo, sea cual fuere nuestra posición en metaética, si somos objetivistas consideraremos que la corrección o incorreción moral de, por ejemplo, el hecho de bombardear los territorios controlados por ISIS en Oriente Medio, depende únicamente de la adecuación de las razones aducidas a favor y en contra de tal hecho. Y nadie está en mejor posición que otro para ello por el hecho de adscribirse a una u otra de las metaéticas que garantizan la objetividad a nuestra práctica moral.

\section{Bibliografía}

Bagnoli, C., "Constructivism in Metaethics", en The Stanford Encyclopedia of Philosophy, Edward N. Zalta (ed.), 2015.

Bentham, J., An Introduction to the Principles of Morals and Legislation, London, Athlone Press, 1970.

Blackburn, S., Essays in Quasi-Realism, Oxford, Oxford University Press, 1993.

${ }^{37}$ Carnap, R., Autobiografia intelectual, trad. de C. Castells, Barcelona, Paidós, 1992. 
Bulygin, E., Essays in Legal Philosophy, Carlos Bernal, Carla Huerta, Tecla Mazzarese, José Juan Moreso, Pablo E. Navarro, and Stanley Paulson (eds.), Oxford: Oxford University Press, 2015.

Carnap, R., Autobiografia intelectual, trad. de C. Castells, Barcelona, Paidós, 1992.

Colyvan, M., "Indispensability Arguments in the Philosophy of Mathematics", en The Stanford Encyclopedia of Philosophy, Spring 2015 Edition, E. N. Zalta (ed.), 2015.

De Lora, P., Justicia para los animales, Madrid, Alianza, 2003.

Dworkin, R., "Objectivity and Truth: You'd Better Believe It", en Philosophy and Public Affairs, 1996. Justice for Hedgehogs, Cambridge, Mass., Harvard University Press, 2011.

Enoch, David, "Why Idealize?", Ethics, 2005. "Agency, Shamgency, Why Normativity Won't Come from What is Constitutive of Agency", en Philosophical Review, 2006. "Rationality, Coherence, Convergence: A Critical Comment on Michael Smith's Ethics and the A Priori", en Philosophical Books, 2007.

"Can there be a Global, Interesting, Coherent Constructivism about Practical Reason?", en Philosophical Explorations, 2009.

Taking Morality Seriously. A Defense of Robust Realism, Oxford, Oxford University Press, 2011.

-"In Defense of Taking Morality Seriously: Reply to Manne, Sobel, Lenman, and Joyce", en Philosophical Studies, 2014.

Estlund, D.M., Democractic Authority: A Philosophical Framework, Princeton: Princeton University Press, 2009.

Faraci, D., "Book Review: David Enoch, Taking Morality Seriously. A Defense of Robust Realism, (Oxford: Oxford University Press, 2011)", en The Journal of Value Enquiry, 2012.

Ferrajoli, L., "Constitucionalismo principialista y constitucionalismo garantista", en Doxa. Cuadernos de Filosofia del Derecho, 2011.

"La scelta come fondamento ultimo della morale", en Teoria Politica, 2012. 
Objetividad moral sin realismo robusto. Comentarios sobre Enoch

Ferrajoli, L.; Ruiz Manero, J., Dos modelos de constitucionalismo. Una conversación, Madrid, Trotta, 2012.

Ferrero, L., "Constitutivism and the Inescapibility of Agency", en Oxford Studies in Metaethics, 2009.

Fine, K., "The Question of Realism", en Philosophers' Imprint, 2001.

Gibbard, A., Thinking How to Live, Cambridge, Mass., Harvard University Press, 2003.

Guastini, R., "Dei rapporti tra liberalismo e non-cognitivismo", en Teoria Politica, 2012.

Habermas, J., "Ética del discurso. Notas para un programa de fundamentación", en Conciencia moral y acción comunicativa, trad. de R. García Cotarelo, Barcelona, Península, 1985.

Hart, H.L.A. Essays on Bentham. Jurisprudence and Political Philosophy, Oxford, Oxford University Press, 1982.

Joyce, R., "Metaethical Pluralism: How both Moral Naturalism and Moral Skepticism May Be Permissible Positions", S. Natucelli, G. Seay (eds.), en Ethical Naturalism: Current Debates, (Cambridge: Cambridge University Press), 2012.

"Book Review: Taking Morality Seriously: A Defense of Robust Realism by Enoch, David", en Ethics, 2013. 2014.

"Taking Moral Skepticism Seriously", en Philosophical Studies,

Kant, I., Lecciones de ética, trad. de R. Rodríguez Aramayo y C. Roldán Panadero, Barcelona, Crítica, 1988.

Korsgaard, C., The Sources of Normativity, Cambridge, Cambridge University Press, 1996

Lenman, J., "Deliberation, Schmeliberation: Enoch's Indispensability Argument", en Philosophical Studies, 2014.

Mackie, J., Ethics. Inventing Right and Wrong, Harmondsworth, Penguin, 1977.

Manne, K., y Sobel, D., "Disagreeing about how to disagree", en Philosophical Studies, 2014.

Marmor, A., "Randomized Judicial Review", 2015. https://blogs. cornell.edu/marmor/files/2015/02/RJR-April-15-revised15s4sav.pdf. 
Martí, J.L., "The Epistemic Conception of Deliberative Democracy Defended. Reasons, Rightness and Equal Political Autonomy", in S. Besson, J.L. Martí (eds.), en Deliberative Democracy and Its Discontents, Aldershot, Ashgate, cap. 2, 2006.

"Democracia y subjetivismo ético", en Teoria Politica, 2012.

Mcdowell, J., "Values and Secondary Qualities" en T. Honderich, Morality and Objectivity, London, Routledge \& Kegan Paul, 1985.

Moore, G.E., "Proof an External World", en Proceedings of the British Academy, 1939.

Mosterín, J., jVivan los animales!, Madrid, Debate, 1998.

Moreso, J.J., "El reino de los derechos y la objetividad de la moral", en Análisis filosófico, 2003. (Ahora en Moreso 2009, ensayo 2).

"El constructivismo ético y el dilema de Eutifrón". Alegre, M., Gargarella, R., Rosenkrantz, C.F, en Homenaje a Carlos S. Nino, Buenos Aires, La Ley, 2008. (Ahora en Moreso 2009, ensayo 4).

La Constitución: modelo para armar, Madrid, Marcial Pons, 2009.

"Antígona como defeater. Sobre el constitucionalismo garantista de Ferrajoli", en Doxa, 2012.

"Donde la pala se nos dobla. De nuevo sobre metaética y política", en Teoría Política, 2013a.

"Ethica more iuridico incorporata: Luigi Ferrajoli", en Anuario de filosofia del derecho, $2013 \mathrm{~b}$.

Nino, C.S., El constructivismo ético, Madrid, Centro de Estudios Constitucionales, 1989.

The Constitution of Deliberative Democracy, New Haven, Yale University Press, 1996.

Parfit, D., On What Matters. Volume Two, Oxford, Oxford University Press, 2011.

Putnam, H., "Philosophy of Logic", reprinted in H. Putnam, en Mathematics Matter and Method: Philosophical Papers, Volume 1, (2nd edition), Cambridge, Cambridge University Press, 1979, pp. 323-357.

Quine, W.V.O., "Things and Their Place in Theories", en W. V.O. Quine, Theories and Things, Cambridge, MA, Harvard University Press, 1981, pp. 1-23. 
Rawls, J., "Kantian Constructivism in Moral Theory", Journal of Philosophy, 77, 1982.

Scanlon, T., What We Owe to Each Other, Cambridge, Mass., Harvard University Press, 1988.

Schroeder, M., "Realism and Reduction: The Quest of Robustness", en Philosopher's Imprint, 5 (1), 2005.

Shafer-Landau, R., Moral Realism: A Defense, Oxford, Oxford University Press, 2003.

Singer, P., Animal Liberation, New York, HarperCollins, 1975.

Smith, M., "A Constitutivist Theory of Reasons: Its Promise and Parts", en Law, Ethics and Philosophy, 1, 2013.

Street, S., "What is Constructivism in Ethics and Metaethics?", en Philosophy Compass, 2010.

Wedgwood, R., The Nature of Normativity, Oxford, Oxford University Press, 2007.

"Book Review: Taking Morality Seriously. A Defense of Robust Realism. By David Enoch, Oxford, Oxford University Press, 2011", en The Philosophical Quarterly, 2013. 
